\begin{tabular}{|c|c|c|c|}
\hline Caco Donarto & Case Rep Gastroenterol & & \\
\hline Gastroenterology & $\begin{array}{l}\text { DOI: 10.1159/000489486 } \\
\text { Published online: May 31, } 2018\end{array}$ & $\begin{array}{l}\text { (c) } 2018 \text { The Author(s) } \\
\text { Published by S. Karger AG, Basel } \\
\text { www.karger.com/crg }\end{array}$ & $\begin{array}{l}\text { Karger } \\
\text { Open access }\end{array}$ \\
\hline & $\begin{array}{l}\text { This article is licensed under } \\
\text { International License (CC BY-I } \\
\text { Usage and distribution for comr }\end{array}$ & $\begin{array}{l}\text { nons Attribution-NonCommercial } \\
\text { ger.com/Services/OpenAccessLice } \\
\text { uires written permission. }\end{array}$ & \\
\hline
\end{tabular}

\title{
Ascaris lumbricoides: A Startling Discovery during Screening Colonoscopy
}

\author{
Jamil Shah $^{\mathrm{a}}$ Abul Shahidullah ${ }^{\mathrm{b}}$ \\ aDepartment of Internal Medicine, The Brooklyn Hospital Center, Academic Affiliate of \\ The Icahn School of Medicine at Mount Sinai, Clinical Affiliate of The Mount Sinai \\ Hospital, Brooklyn, NY, USA; 'b Department of Medicine, Henry J. Carter Specialty Hospital \\ and Nursing Facility, New York, NY, USA
}

\section{Keywords}

Ascaris lumbricoides · Ascariasis · Roundworms · Screening colonoscopy

\begin{abstract}
Intestinal parasitic infections are a major public health issue across the world and particularly in rural and urban areas of tropical and subtropical countries. Those at increased risk include inhabitants of poor and disadvantaged regions, which are more likely to have inadequate environmental sanitation, insufficient water supply, greater contact rates with reservoirs of infection, limited health literacy, and socioeconomic disparities. Of the intestinal nematodes (roundworms) that parasitize the human gastrointestinal tract, Ascaris lumbricoides is the largest in terms of size. It causes ascariasis, a "neglected tropical disease," or NTD, that is among the most common helminthic human infections worldwide with an estimated 800 million to 1.2 billion people infected. It causes more than 60,000 deaths annually. However, in more than $85 \%$ of cases, infections do not result in symptoms - especially in individuals infected with a small number of worms. Thus, many individuals with intestinal ascariasis remain undiagnosed for years until either they experience symptoms and seek medical attention, the macroscopic adult worms are passed with the stool, or the adult worms are incidentally discovered during routine endoscopic procedures. Here, we present an interesting case of an elderly Bangladeshi man with seemingly innocuous complaints of intermittent mild abdominal symptoms and no recent travel history, who was discovered to have intestinal ascariasis during a screening colonoscopy.

(C) 2018 The Author(s)

Published by S. Karger AG, Basel
\end{abstract}




\section{Case Reports in Gastroenterology}

Case Rep Gastroenterol 2018;12:224-229

DOI: 10.1159/000489486

(c) 2018 The Author(s). Published by S. Karger AG, Basel www.karger.com/crg

Shah and Shahidullah: Ascaris lumbricoides: A Startling Discovery during Screening Colonoscopy

\section{Introduction}

The soil-transmitted helminths include Ascaris lumbricoides, as well as whipworm (Trichuris trichiura), hookworm (Ancylostoma duodenale and Necator americanus), and Strongyloides stercoralis. Over one-quarter of the world's population is at risk for infection [1]. Worldwide, in 2010, an estimated 819.0 million individuals were infected with A. lumbricoides, 464.6 million individuals were infected with whipworms, and 438.9 million individuals were infected with hookworms [2]. Infection with $A$. lumbricoides, like other parasitic nematodes, is more common in rural populations where sanitation facilities are unsatisfactory, in temperate, humid regions along the equator. Infection occurs in urban populations as well. These communities are subjected to a vicious cycle of malnourishment and reinfections, resulting in continuous morbidity.

By comparison, in the United States, the prevalence of ascariasis has declined considerably since modern sanitation and waste management were introduced at the turn of the twentieth century [3]. However, cases still occur due to emigration from, and travel outside the United States to, areas with a high prevalence of infection. Most individuals infected with $A$. lumbricoides are asymptomatic, and clinical symptoms are mainly confined to patients with relatively high worm loads [2]. Here, we present a case of intestinal ascariasis diagnosed during a screening colonoscopy in an elderly Bangladeshi man with seemingly innocuous complaints of intermittent mild abdominal symptoms.

\section{Case Presentation}

A 50-year-old Bangladeshi man, with past medical history of hypertension, hyperlipidemia, and diabetes mellitus, was referred to our gastroenterology practice for a screening colonoscopy. During the initial encounter, he reported experiencing diffuse mild abdominal discomfort, along with bloating, belching, decreased appetite, and a vague sensation of feeling full earlier than expected when eating. In fact, he had experienced these symptoms intermittently for several years but had never sought medical attention for them. He denied any recent symptoms of vomiting, constipation, diarrhea, blood in the stool, black stools, dysphagia, or weight loss. He reported that none of his family members had experienced similar symptoms. He denied any recent history of travel outside the United States, although he had emigrated from Bangladesh more than 10 years earlier and most recently visited the country 3 years ago. His social history was remarkable for a cigarette smoking history of 10 pack-years. He denied any alcohol use or illicit drug use. And, he denied any drug allergies.

On physical exam, the patient appeared exhausted. He was afebrile (temperature $97.6^{\circ} \mathrm{F}$ ) and hemodynamically stable (pulse rate $68 \mathrm{bpm}$, blood pressure 142/85 $\mathrm{mm} \mathrm{Hg}$ ). The abdomen was soft and not distended with no tenderness and normoactive bowel sounds. There was no guarding nor rigidity. Laboratory testing was performed. The serum electrolytes, complete blood count, and thyroid function tests were within normal limits. There was neither anemia nor any eosinophilia. His hemoglobin A1c level was at goal.

The following week, the patient underwent colonoscopy. The colonoscope was passed with no difficulty to the cecum. However, a live parasite, approximately $25 \mathrm{~cm}$ in length and $6 \mathrm{~mm}$ in diameter, was visualized in the transverse colon (Fig. 1a, b). The colonoscopy also revealed multiple polyps, ranging in size from 4 to $6 \mathrm{~mm}$, in the rectosigmoid colon. Intact removal of the intestinal parasite was achieved with a snare, and it was sent for histopathologic evaluation where it was identified as an adult $A$. lumbricoides worm (Fig. 2). Biopsies 


\section{Case Reports in Gastroenterology}

Case Rep Gastroenterol 2018;12:224-229

DOI: 10.1159/000489486

(c) 2018 The Author(s). Published by S. Karger AG, Basel www.karger.com/crg

Shah and Shahidullah: Ascaris lumbricoides: A Startling Discovery during Screening Colonoscopy

were performed on all of the polyps and also sent for histopathologic evaluation, which showed hyperplastic polyp for all of the polyps. Also, at a later date, his stool was collected for ova and parasites. Stool microscopy was performed and a wet mount of the stool $(\times 400$ magnification) revealed the ovum of $A$. lumbricoides (Fig. 3).

The patient was treated with anti-helminthic therapy with albendazole $400 \mathrm{mg}$ orally as a single dose. After 1 month, he reported no further symptoms. Presently, he is living an asymptomatic, healthy life with his family.

\section{Discussion}

Ascaris lumbricoides is a nematode, or roundworm, that parasitizes the human gastrointestinal tract. Worldwide, ascariasis is among the most common helminthic human infections with an estimated 800 million to 1.2 billion people infected, and it causes more than 60,000 deaths annually $[4,5]$. In fact, ascariasis is considered one of the "neglected tropical diseases," or NTDs - a diverse group of infectious diseases that exist in tropical and subtropical environments in 149 countries across the world, and which affect more than 1 billion individuals, costing developing economies billions of dollars each year $[4,6]$.

The fact that $A$. lumbricoides can produce copious numbers of eggs that can survive extreme environmental conditions has made it one of the most prevalent and geographically well-distributed parasitic worms in impoverished socioeconomic regions across the world [7]. In the United States, the occurrence of ascariasis is attributed to immigration from, and travel outside the country to, areas with high prevalence of infection. However, the southeastern region of the United States, due to its temperate, humid climate, has the highest burden of the disease [8].

In the life cycle of $A$. lumbricoides, the definitive host for infection is human and the mode of transmission is the fecal-oral transfer of embryonated eggs. After oral ingestion, via contaminated food or water, the eggs hatch in the small intestine within 4 days and release larvae. The larvae penetrate intestinal walls and enter the portal venous system and lymphatic channels, where they migrate hematogenously and via lymphatics to the liver and then the lungs. There, the larvae move toward and into the alveoli where they mature over a period of 10-14 days, make their way up the tracheobronchial tree to reach the hypopharynx, and are swallowed once more. After returning to the small intestine, these larvae mature into adult worms (females reaching 20-35 cm in length; males reaching 15-30 cm in length) that live in the lumen, typically of the jejunum or ileum. When both female and male adult worms coexist, the females produce fertilized eggs that are passed into the stool. One female adult $A$. lumbricoides worm inhabiting the small intestine produces approximately 200,000 eggs each day [9]. Under warm, shady, and moist conditions, the eggs can remain viable in soil for up to 10 years and require only 10 to 15 days' time in soil to become infective. Thus, the arrival of larvae back to the small intestine concludes the extraintestinal migration of larvae and begins another molting to become adult worms $[4,10]$.

Intestinal ascariasis should be suspected in individuals from endemic areas who present with vague nonspecific abdominal symptoms, such as pain, discomfort, dyspepsia, distention, nausea, vomiting, diarrhea, and anorexia, and/or with associated complications, such as intestinal obstruction and hepatobiliary or pancreatic involvement [10]. In endemic regions, patients with high worm loads of $A$. lumbricoides often present with acute intestinal obstruction. Ochoa [11] studied 311 cases over a period of 25 years from 1963 to 1988. He reported that substantial intestinal infestation, together with the propensity of the worms to interlace and 
form large masses, often resulted in intestinal obstruction as well as the classic symptoms of abdominal pain, constipation, and vomiting [11]. Intestinal obstruction may also be complicated by appendicitis, intussusception, volvulus, and volvulus with gangrene and perforation $[11,12]$. Furthermore, the worms can penetrate biliary and pancreatic ducts, resulting in biliary colic, as well as hepatic and pancreatic dysfunction. The presentation should correlate with relevant epidemiologic exposures, such as to locations with high prevalence of soil-transmitted helminths. The diagnosis of intestinal ascariasis is confirmed via stool microscopy for ova or via detection and examination of adult worms.

Management of the disease and its associated complications consists of anti-helminthic therapy. The mainstays of treatment for ascariasis at this time are albendazole $400 \mathrm{mg}$ orally as a single dose or mebendazole (500 mg orally as a single dose or $100 \mathrm{mg}$ orally twice daily for 3 days). In order to treat pregnant women, pyrantel pamoate $11 \mathrm{mg} / \mathrm{kg}$ orally as a single dose, up to a maximum of $1 \mathrm{~g}$, is currently recommended. In certain cases, such as with the complications reported above, surgical and/or endoscopic interventions may be necessary.

\section{Conclusions}

In short, intestinal parasitic infections, such as ascariasis, are a significant global health issue, particularly in rural and urban areas of tropical and subtropical developing countries. Patients may present with vague nonspecific abdominal symptoms, or, as in this case, the adult worm may be incidentally discovered during a routine endoscopic procedure. Making the diagnosis depends on the timing of the life cycle. For instance, eosinophilia is typically present only during migration of the larvae to the lungs, and stool microscopy will reveal ova only during the intestinal phase. Either way, ascariasis should be considered in the differential diagnosis of dyspepsia in individuals who emigrate from endemic areas. Treatment of patients is essential as, without it, $A$. lumbricoides will continue to cause repeated complications throughout the life cycle.

\section{Statement of Ethics}

The authors have no ethical conflicts to disclose.

\section{Disclosure Statement}

The authors of this case report declare that they have no competing interests. The authors declare that they have no affiliations with or involvement in any organization or entity with any financial interest or nonfinancial interest (such as personal or professional relationships, affiliations, knowledge, or beliefs) in the subject matter discussed in the manuscript.

\section{Funding Sources}

The authors of this case report declare that no financial support nor grant support has been received for the preparation of the manuscript. 
Shah and Shahidullah: Ascaris lumbricoides: A Startling Discovery during Screening Colonoscopy

\section{References}

1 Jourdan PM, Lamberton PH, Fenwick A, Addiss DG. Soil-transmitted helminth infections. Lancet. 2017 Sep;S0140-6736(17)31930-X.

2 Pullan RL, Smith JL, Jasrasaria R, Brooker SJ. Global numbers of infection and disease burden of soil transmitted helminth infections in 2010. Parasit Vectors. 2014 Jan;7(1):37.

3 Starr MC, Montgomery SP. Soil-transmitted Helminthiasis in the United States: a systematic review-19402010. Am J Trop Med Hyg. 2011 Oct;85(4):680-4.

4 de Lima Corvino DF, Bhimji SS. Ascariasis. StatPearls [Internet]. Treasure Island, FL: StatPearls Publishing; 2018 [updated 2017 May 25].

5 Hadush A, Pal M. Ascariasis: Public Health Importance and its Status in Ethiopia. Air Water Borne Diseases. 2016 Jun;5(1):126.

6 Deribew A, Kebede B, Tessema GA, Adama YA, Misganaw A, Gebre T et al. Mortality and Disability-Adjusted Life-Years (Dalys) for Common Neglected Tropical Diseases in Ethiopia, 1990-2015: Evidence from the Global Burden of Disease Study 2015. Ethiop Med J. 2017;55 Suppl 1:3-14.

7 Kanchan T, Wasti H, Acharya J. Gastro-intestinal ascariasis-an unusual autopsy case report. Med Leg J. 2015 Sep;83(3):139-41.

8 Tietze PE, Tietze PH. The roundworm, Ascaris lumbricoides. Prim Care. 1991 Mar;18(1):25-41.

9 Bethony J, Brooker S, Albonico M, Geiger SM, Loukas A, Diemert D et al. Soil-transmitted helminth infections: ascariasis, trichuriasis, and hookworm. Lancet. 2006 May;367(9521):1521-32.

10 Dold C, Holland CV. Ascaris and ascariasis. Microbes Infect. 2011 Jul;13(7):632-7.

11 Ochoa B. Surgical complications of ascariasis. World J Surg. 1991 Mar-Apr;15(2):222-7.

12 López L, Cáceres R, Servin J, Esquivel J, Chirico M, Rodriguez-Morales AJ. Surgical diagnosis and management of intestinal obstruction due to Ascaris lumbricoides. Surg Infect (Larchmt). 2010 Apr;11(2):183-5.
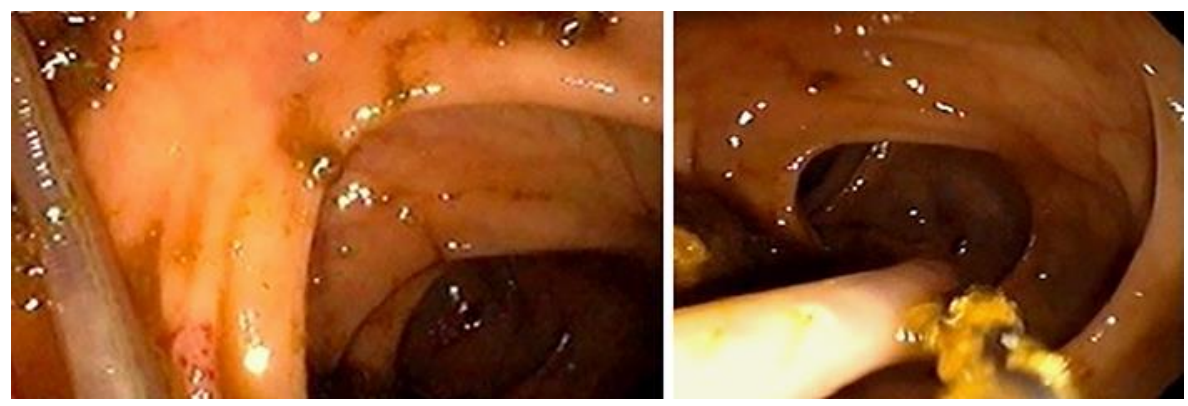

Fig. 1. a, $\mathbf{b}$ The adult $A$. lumbricoides worm visualized in the transverse colon during the patient's screening colonoscopy. 


\section{Case Reports in Gastroenterology} www.karger.com/crg

Shah and Shahidullah: Ascaris lumbricoides: A Startling Discovery during Screening Colonoscopy

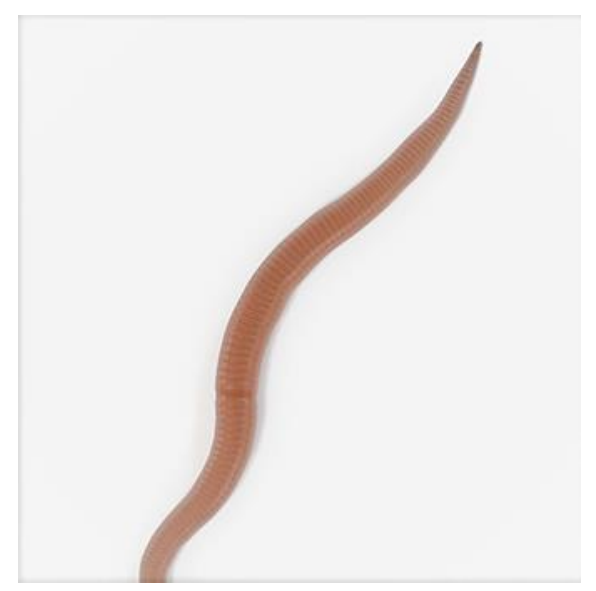

Fig. 2. The same adult $A$. lumbricoides worm, approximately $25 \mathrm{~cm}$ in length and $6 \mathrm{~mm}$ in diameter, after intact removal during the patient's colonoscopy.

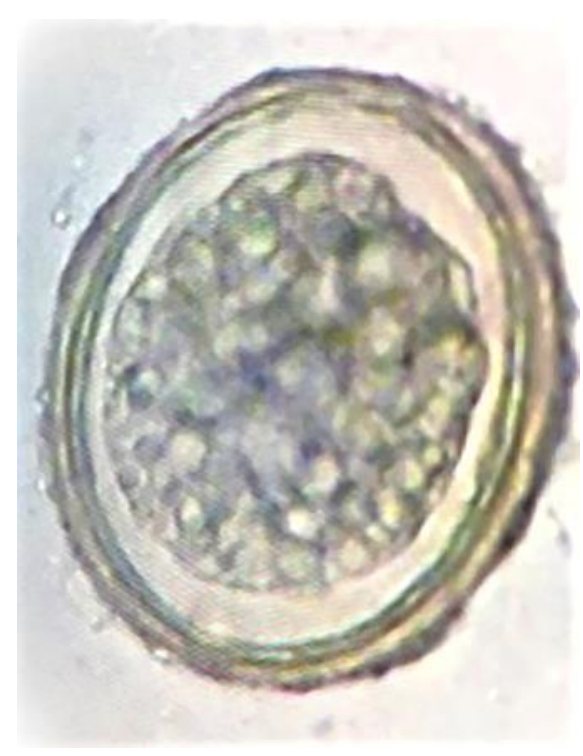

Fig. 3. Wet mount of stool from the patient's stool microscopy showing the ovum of A. lumbricoides. $\times 400$ magnification. 